
\title{
6

\section{Endoscopic Stenting for Malignant Biliary Obstruction: Results of a Nationwide Experience}

\author{
Jeanne Lubbe ${ }^{1,2}$, Gabriel Sandblom ${ }^{3}$, Urban Arnelo ${ }^{4}$, Eduard Jonas ${ }^{5}$ and Lars Enochsson ${ }^{4}$ \\ ${ }^{1}$ Department of Clinical Sciences, Intervention and Technology, Centre for Digestive Diseases, Karolinska Institutet, Karolinska \\ University Hospital, Stockholm, Sweden, ${ }^{2}$ University of Stellenbosch, Department of Surgical Sciences, Division of Surgery, Tygerberg \\ Hospital, Bellville, South Africa, ${ }^{3}$ Department of Clinical Science and Education Södersjukhuset, Karolinska Institutet, Department of \\ Surgery, Södersjukhuset, Stockholm, ${ }^{4}$ Department of Surgical and Perioperative Sciences, Umeå University, Umeå University Hospital, \\ Umeå, Sweden, ${ }^{5}$ Department of Surgery, University of Cape Town Faculty of Health Sciences, Surgical Gastroenterology Unit, Groote \\ Schuur Hospital, Cape Town, Bellville, South Africa
}

Background/Aims: Many unanswered questions remain about the treatment of malignant hilar obstruction. We investigated endoscopic stenting for malignant biliary strictures, as reported in a nationwide registry.

Methods: All endoscopic retrograde cholangiopancreatography (ERCP) procedures entered in the Swedish Registry of Gallstone Surgery and ERCP from January 2010 to December 2017 in which stenting was performed for malignant biliary stricture management were included in this study. Patency was estimated by determining the time to reintervention.

Results: Endoscopic stenting was performed for malignant stricture management in 4623 ERCP procedures, of which 1364 (29.5\%) were performed for hilar strictures. Of the hilar strictures, 320 (23.5\%) were intrahepatic strictures (Bismuth-Corlette IIIIV). Adverse events were more common after hilar stenting than after distal stenting $(17.2 \%$ vs. $12.0 \%, p<0.0001)$. The 6 -month reintervention rate was $73.4 \%$ after hilar stenting compared with $55.9 \%$ after distal stenting $(p<0.0001)$. The 6 -month reintervention rates for Bismuth-Corlette types I, II, IIIa, IIIb, and IV were $70.4 \%, 75.6 \%, 90.0 \%, 87.5 \%$, and $85.7 \%$, respectively. In multivariate analysis, the risk for reintervention was three times higher after hilar stenting than after distal stenting (hazard ratio $3.47,95 \%$ confidence interval 2.01-6.00, $p<0.001$ ).

Conclusions: This study with a relatively large patient cohort undergoing endoscopic stenting confirms that stenting for malignant hilar obstruction has more adverse events and lower patency than stenting for distal malignant obstruction. Clin Endosc 2021;54:713-721

Key Words: Endoscopic; Hilar; Malignant; Obstruction; Stent

\section{INTRODUCTION}

Although multiple issues about the management and outcomes of malignant biliary strictures have been addressed in a number of study formats, few studies to date have compared

Received: December 6, 2020 Revised: February 25, 2021 Accepted: March 15, 2021

Correspondence: Jeanne Lubbe

University of Stellenbosch, Department of Surgical Sciences, Division of Surgery, Tygerberg Hospital, PO Box 1714, Bellville 7535, South Africa Tel: +27-72-207-6674, Fax: +27-86-559-5853, E-mail: jeanne.lubbe@ki.se ORCID: https://orcid.org/0000-0001-8397-8685

(c) This is an Open Access article distributed under the terms of the Creative Commons Attribution Non-Commercial License (http://creativecommons.org/ licenses/by-nc/3.0) which permits unrestricted non-commercial use, distribution, and reproduction in any medium, provided the original work is properly cited. the outcomes of endoscopic stenting specifically according to different locations in the biliary tree. A number of randomized trials have shown the superiority of self-expanding metal stents (SEMSs) over plastic stents for both distal strictures (DSs) and hilar strictures (HSs). ${ }^{1,2}$ The equivalence of covered and uncovered SEMSs for DSs has been confirmed in numerous studies. ${ }^{3}$ In contrast, although hilar stenting is inherently more complex and generates more questions, fewer studies with generally lower levels of evidence and weaker treatment recommendations are available concerning the management of HSs. More data from unselected populations are necessary to assess the outcome of stenting as practiced in the community at large.

In this respect, a number of controversies and unanswered questions remain about the management of malignant HSs. 
The percentage of liver volume that needs to be drained to achieve symptom control in advanced Bismuth-Corlette (B-C) types is a topic of ongoing debates, with evidence supporting both $30 \%$ (unilateral stenting) and 50\% (requiring multiple or bilateral stenting) ${ }^{4-7}$ Studies with relatively small patient cohorts are complicated by multiple possible confounders. These include variations in the complexity and definition of strictures (level, extent, and multiplicity), access used for stent placement (transhepatic vs. transpapillary), and different stent configurations (stent-in-stent vs. side-by-side) in patients with B-C type III-IV strictures.

Therefore, we designed this study in which the aforementioned confounders were minimized to answer a specific research question based on prospective data from a well-validated and large population-based registry. The purpose of this study was to assess endoscopic stenting for malignant biliary obstruction according to stricture location (distal vs. hilar, further subdivided into the different hilar B-C types). The primary endpoints were procedural and 30-day adverse events, and the secondary endpoint was the need for reintervention.

\section{MATERIALS AND METHODS}

\section{Study design}

This study conformed to the provisions of the Declaration of Helsinki and was approved by the Stockholm Regional Research Ethics Committee (EPN no. 2018/277-31). Since May 2005, endoscopic retrograde cholangiopancreatography (ERCP) procedures performed in Sweden have been entered into the Swedish Registry of Gallstone Surgery and ERCP (GallRiks, http:/www.ucr.uu.se/gallriks). This nationwide registry, covering $>90 \%$ of all hospitals in Sweden, has confirmed high validity and follow-up frequency, offering reliable information on indications, prevailing ERCP practice, nature and technical success of interventions, and adverse events. ${ }^{8,9}$

All ERCP procedures performed for malignant biliary obstruction and entered into GallRiks between January 1, 2010, and December 31, 2017, were assessed for inclusion in the study (Fig. 1). During this period, endobiliary radiofrequency ablation has not yet been introduced in Sweden. Only index procedures performed for malignant strictures in which the diagnosis was confirmed on cytology/histology or at a multidisciplinary team discussion (based on tumor markers and imaging) were included. Patients in whom the International Classification of Diseases $10^{\text {th }}$ revision coding did not confirm malignancy (bile duct stones [K80] and indeterminate strictures [K83]) were excluded. Likewise, patients who did not receive a stent because of unsuccessful cannulation or an inability to cross the stricture with a guidewire (complete ste- nosis) were excluded. Patients in whom the stricture or stent position was not indicated (missing data) were further excluded. Therefore, only patients with malignant biliary obstruction with known positions of both the stricture/s and stent/s were included in the analysis of adverse events. To calculate the stent failure rate, patients in whom a plastic stent or a combination of a plastic stent and a SEMS was placed, as well as patients in whom multiple SEMSs were applied at the index ERCP were excluded, such that only patients who received a single SEMS were analyzed.

The analyzed data included sex, age, and American Society of Anesthesiologists (ASA) physical status classification. Procedural information included the anatomical location of the stricture (divided into DS and HS, with a further subdivision into extrahepatic HS [B-C I-II] and intrahepatic HS [B-C IIIIV]) and the total procedure time. Both intraprocedural and 30-day postprocedural adverse events were documented. In patients who required endoscopic reintervention, the time to reintervention was compared between DSs and HSs, as well as among HSs subdivided into different B-C types. All patients were followed up until December 31, 2018. The date of death in deceased patients was determined by cross-referencing with the Swedish Central Death Register.

\section{Definitions}

The index procedure was defined as the first ERCP procedure performed. The most proximal stricture extension was used as a reference point for defining the stricture location. A DS was defined as an obstruction situated either in the ampulla of Vater or the common bile duct (ductus choledochus), distal to the cystic duct junction. An HS was defined as an obstruction involving or situated proximal to the cystic duct junction in the common hepatic duct (ductus hepaticus) and/ or left and/or right hepatic ducts, and HSs were subdivided according to the modified $\mathrm{B}-\mathrm{C}$ classification. ${ }^{10}$ The total procedure time was defined as the time from endoscope insertion to the time of scope removal.

Adverse events were defined according to internationally accepted consensus criteria, in which pancreatitis is defined as abdominal pain in the presence of an increase in serum amylase levels to at least three times the normal level and cholangitis is defined as a new onset temperature $>38^{\circ} \mathrm{C}$ at $>24 \mathrm{~h}$ after the procedure combined with cholestasis. ${ }^{11}$ The timing of adverse events was classified as intraprocedural or postprocedural ( $\leq 30$ days). The time to the need for endoscopic reintervention (owing to symptoms associated with recurrent obstruction) was used as a proxy for stent failure or patency regardless of cause (occlusion or migration), according to the Tokyo criteria for reporting on transpapillary biliary stenting. ${ }^{12}$ 


\section{Statistical analysis}

All statistical analyses were performed using JMP Pro 14.2.0 (SAS Institute Inc., Cary, NC, USA). Descriptive statistics were used for demographic and clinical parameters, procedure time, and adverse events, with Pearson's chi-square test used for categorical data and Student's t-test for continuous data. Stent failure and stent patency were calculated using the Kaplan-Meier method, and Cox proportional hazard analysis was used to assess the influence of sex, age, ASA score, and stricture location on the risk of reintervention. Endoscopic reintervention was considered a terminal event, whereas death or reaching the end of the study period with a functioning stent was treated as a censored event.

\section{RESULTS}

Of 58,981 ERCP procedures registered during the inclusion period, 4623 fulfilled the inclusion criteria (Fig. 1). Of the patients, $70.5 \%$ had a DS $(n=3,259)$ and $29.5 \%$ had an

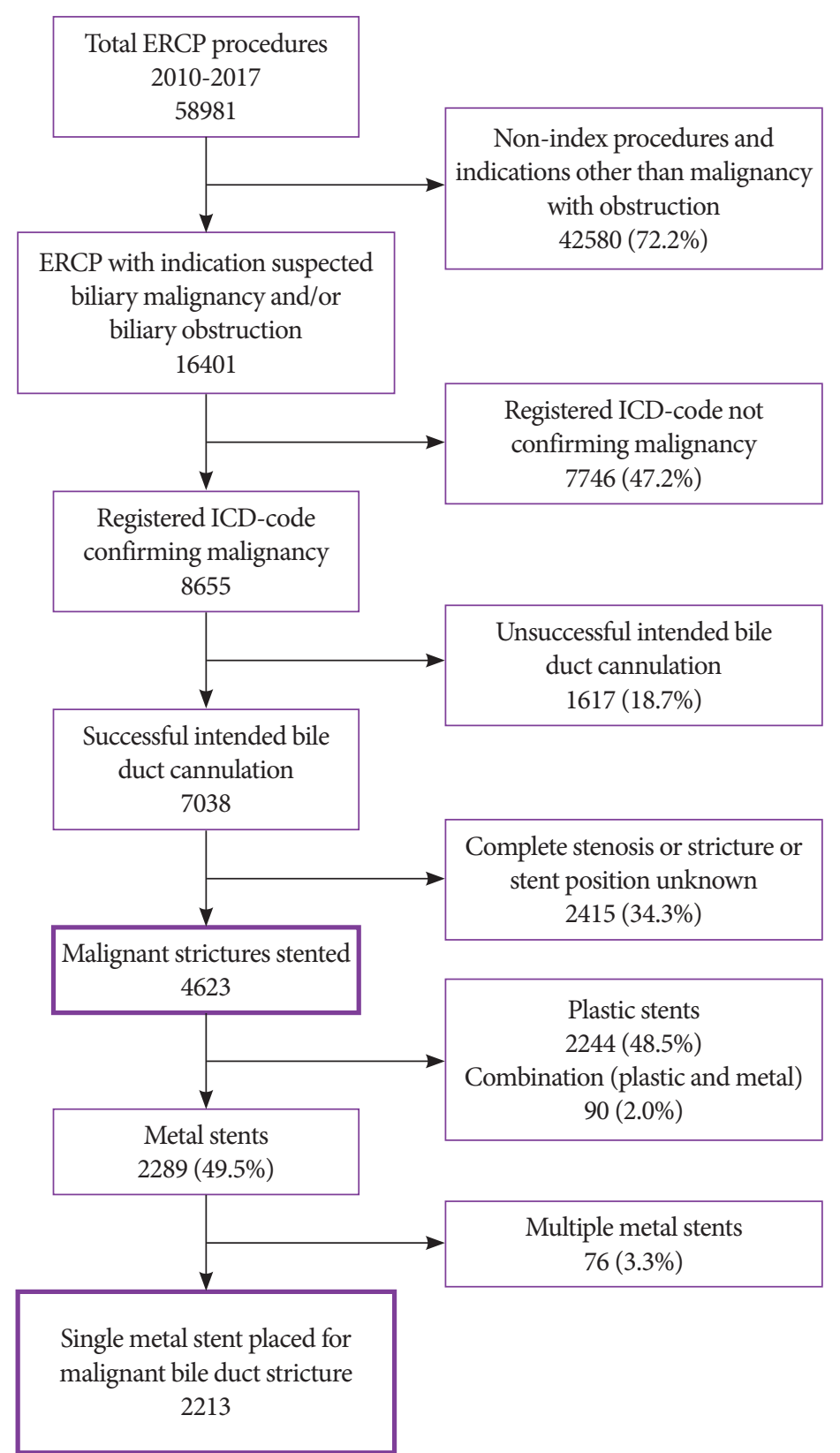

Fig. 1. Flowchart of the included ERCP procedures in this study. ERCP, endoscopic retrograde cholangiopancreatography; ICD, International Classification of Diseases. 
HS ( $n=1,364)$, with $76.5 \%$ of the HS cases being B-C type I or II (Fig. 2). The demographic parameters, ASA category, procedure time, and adverse events in patients stented for a DS or an HS are presented in Table 1. Patients undergoing

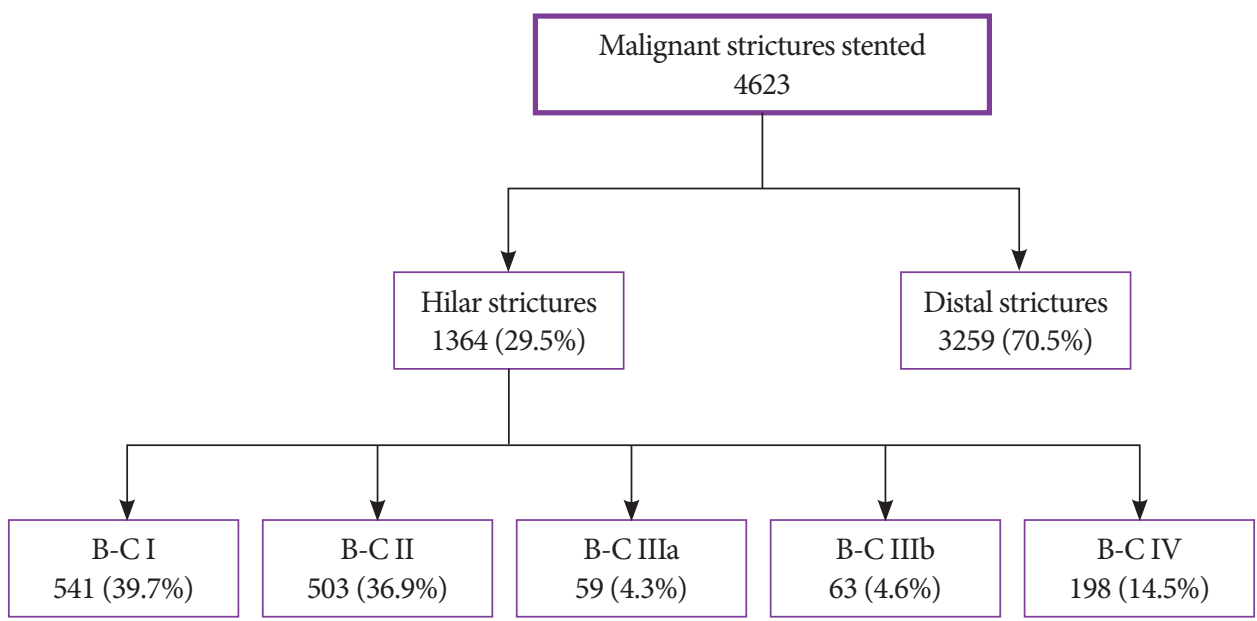

Fig. 2. Flowchart indicating the position of strictures. B-C, Bismuth-Corlette.

Table 1. Demographic Details, Procedural Information, and Adverse Events Comparing Endoscopic Transpapillary Stenting for Distal versus Hilar Strictures

\begin{tabular}{|c|c|c|c|c|}
\hline & & $\begin{array}{c}\text { Distal } \\
n=3,259 \\
n(\%) \text { or mean }(\mathrm{SEM})\end{array}$ & $\begin{array}{c}\text { Hilar } \\
n=1,364 \\
n(\%) \text { or mean (SEM) }\end{array}$ & $p$-Value \\
\hline \multicolumn{5}{|c|}{ Demographic, clinical, and procedural details } \\
\hline \multirow{2}{*}{ Sex } & Female & $1,670(51.2)$ & $750(55.0)$ & \multirow{2}{*}{$0.0201^{\mathrm{a}}$} \\
\hline & Male & $1,589(48.8)$ & $614(45.0)$ & \\
\hline Age (yrs) & & $72.5(0.2)$ & $71.4(0.3)$ & $0.0054^{\mathrm{b}}$ \\
\hline \multirow{2}{*}{ ASA classification } & ASA I-II & $1,938(59.5)$ & $638(46.8)$ & \multirow{2}{*}{$<0.0001^{\mathrm{a}}$} \\
\hline & ASA III-IV & $1,321(40.5)$ & $726(53.2)$ & \\
\hline Procedure time (mi & & $36.9(0.4)$ & $51.9(0.8)$ & $<0.0001^{\mathrm{b}}$ \\
\hline \multicolumn{5}{|l|}{ Adverse events } \\
\hline Total & & $462(14.2)$ & $262(19.2)$ & $<0.0001^{\mathrm{a}}$ \\
\hline Intraprocedural & & $71(2.2)$ & $28(2.1)$ & $0.7876^{\mathrm{a}}$ \\
\hline \multicolumn{2}{|c|}{ Bleeding requiring intervention } & $6(0.2)$ & $0(0)$ & $0.1128^{\mathrm{a}}$ \\
\hline \multicolumn{2}{|c|}{ Extravasation of contrast } & $37(1.1)$ & $12(0.9)$ & $0.4390^{\mathrm{a}}$ \\
\hline \multicolumn{2}{|c|}{ Other intraprocedural complication } & $28(0.9)$ & $16(1.2)$ & \\
\hline \multicolumn{2}{|c|}{ Postprocedural (30-day) } & $391(12.0)$ & $234(17.2)$ & $<0.0001^{\mathrm{a}}$ \\
\hline \multicolumn{2}{|l|}{ Pancreatitis } & $129(4.0)$ & $90(6.6)$ & $0.0001^{\mathrm{a}}$ \\
\hline \multicolumn{2}{|l|}{ Cholangitis } & $92(2.8)$ & $56(4.1)$ & $0.0239^{\mathrm{a}}$ \\
\hline \multicolumn{2}{|l|}{ Perforation } & $9(0.3)$ & $3(0.2)$ & $0.7319^{\mathrm{a}}$ \\
\hline \multicolumn{2}{|l|}{ Bleeding } & $26(0.8)$ & $13(1.0)$ & $0.5985^{\mathrm{a}}$ \\
\hline \multicolumn{2}{|c|}{ Other postprocedural complication } & $135(4.1)$ & $72(5.3)$ & \\
\hline
\end{tabular}

ASA, American Society of Anesthesiologists; SEM, standard error of mean.

${ }^{a}$ Pearson's chi-square test.

${ }^{\mathrm{b}}$ Student's t-test. 
hilar stenting had a mean age of 71.4 years $(p=0.0054)$, and $55 \%$ of them were women $(p=0.0201)$. Patients stented for HS more often had an ASA III or IV status ( $53.2 \%$ vs. $40.5 \%$, $p<0.0001$ ) and a longer mean procedure time (51.9 vs. 36.9 min, $p<0.0001)$. Postprocedural (30-day) adverse events were significantly more common after hilar stenting $(17.2 \%$ vs. $12.0 \%, p<0.0001$ ), with pancreatitis occurring in $6.6 \%$ of patients stented for HSs compared with $4.0 \%$ of patients stented for DSs ( $p=0.0001)$. The incidence of postprocedural cholangitis was higher after hilar stenting than after distal stenting $(4.1 \%$ vs. $2.8 \%, p=0.0239)$.

When specific B-C types were compared, patients with intrahepatic strictures (B-C III-IV) were younger (mean age 68.8 vs. 72.3 years, $p<0.0001)$ and had a longer mean procedure time (65.9 vs. $47.6 \mathrm{~min}, p<0.001)$ than patients with extrahepatic strictures (B-C I-II) (Table 2). Both intraprocedural and 30-day postprocedural adverse events did not significantly differ between extrahepatic and intrahepatic strictures $(2.2 \%$ vs. $1.6 \%[p=0.4796]$ and $17.7 \%$ vs. $15.3 \%,[p=0.3175])$.

Fig. 3 shows the time to the need for reintervention after stent placement for hilar versus distal malignant obstruction. Reintervention within 6 months after stent placement was performed in $73.4 \%$ of the patients stented for HSs compared with $55.9 \%$ of patients stented for DSs $(p<0.0001)$. At 12 months, the percentage of patients who had not required reintervention was $11.2 \%$ in the hilar stenting group and $22.9 \%$ in the distal stenting group $(p<0.0001)$. Reintervention within 6 months after stent placement was performed in $70.4 \%$, $75.6 \%, 90.0 \%, 87.5 \%$, and $85.7 \%$ of B-C I, II, IIIa, IIIb, and IV cases, respectively (Fig. 4). In multivariate analysis taking into account sex, age, and ASA category, male sex and HS location were identified as significant risk factors for reintervention. A three times higher risk of reintervention was observed in patients with an HS (hazard ratio 3.47, 95\% confidence interval

Table 2. Demographic Details, Procedural Information, and Adverse Events Comparing Endoscopic Transpapillary Sstenting for Extrahepatic Hilar Strictures (B-C III) versus Intrahepatic Hilar Strictures (B-C III-IV)

\begin{tabular}{|c|c|c|c|c|}
\hline & & $\begin{array}{c}\text { Extrahepatic (B-C I-II) } \\
n=1,044 \\
n(\%) \text { or mean (SEM) }\end{array}$ & $\begin{array}{c}\text { Intrahepatic (B-C III-IV) } \\
n=320 \\
n(\%) \text { or mean (SEM) }\end{array}$ & $p$-Value \\
\hline \multicolumn{5}{|c|}{ Demographic, clinical, and procedural details } \\
\hline \multirow{2}{*}{ Sex } & Female & $594(56.9)$ & $156(48.7)$ & \multirow{2}{*}{$0.0104^{\mathrm{a}}$} \\
\hline & Male & $450(43.1)$ & $164(51.3)$ & \\
\hline Age (yrs) & & $72.3(0.4)$ & $68.8(0.7)$ & $<0.0001^{\mathrm{b}}$ \\
\hline \multirow{2}{*}{ ASA classification } & ASA I-II & $503(48.2)$ & $135(42.2)$ & \multirow{2}{*}{$0.0602^{\mathrm{a}}$} \\
\hline & ASA III-IV & $541(51.8)$ & $185(57.8)$ & \\
\hline Procedure time $(\mathrm{m}$ & & $47.6(0.9)$ & $65.9(2.1)$ & $<0.001^{\mathrm{b}}$ \\
\hline \multicolumn{5}{|l|}{ Adverse events } \\
\hline Total & & $208(19.9)$ & $54(16.9)$ & $0.3589^{\mathrm{a}}$ \\
\hline Intraprocedural & & $23(2.2)$ & $5(1.6)$ & $0.4796^{\mathrm{a}}$ \\
\hline \multicolumn{2}{|c|}{ Bleeding requiring intervention } & $0(0)$ & $0(0)$ & \\
\hline \multicolumn{2}{|c|}{ Extravasation of contrast } & $11(1.1)$ & $1(0.3)$ & $0.2142^{\mathrm{a}}$ \\
\hline \multicolumn{2}{|c|}{ Other intraprocedural complication } & $12(1.1)$ & $4(1.3)$ & \\
\hline \multicolumn{2}{|c|}{ Postprocedural (30-day) } & $185(17.7)$ & $49(15.3)$ & $0.3175^{\mathrm{a}}$ \\
\hline \multicolumn{2}{|l|}{ Pancreatitis } & $74(7.1)$ & $16(5.0)$ & $0.1880^{\mathrm{a}}$ \\
\hline \multicolumn{2}{|l|}{ Cholangitis } & $44(4.2)$ & $12(3.8)$ & $0.7141^{\mathrm{a}}$ \\
\hline \multicolumn{2}{|l|}{ Perforation } & $2(0.2)$ & $1(0.3)$ & $0.6862^{\mathrm{a}}$ \\
\hline \multicolumn{2}{|l|}{ Bleeding } & $9(0.9)$ & $4(1.3)$ & $0.5321^{\mathrm{a}}$ \\
\hline \multicolumn{2}{|c|}{ Other postprocedural complication } & $56(5.4)$ & $16(5.0)$ & \\
\hline
\end{tabular}

ASA, American Society of Anesthesiologists; B-C, Bismuth-Corlette; SEM, standard error of mean.

${ }^{a}$ Pearson's chi-square test.

bstudent's t-test. 


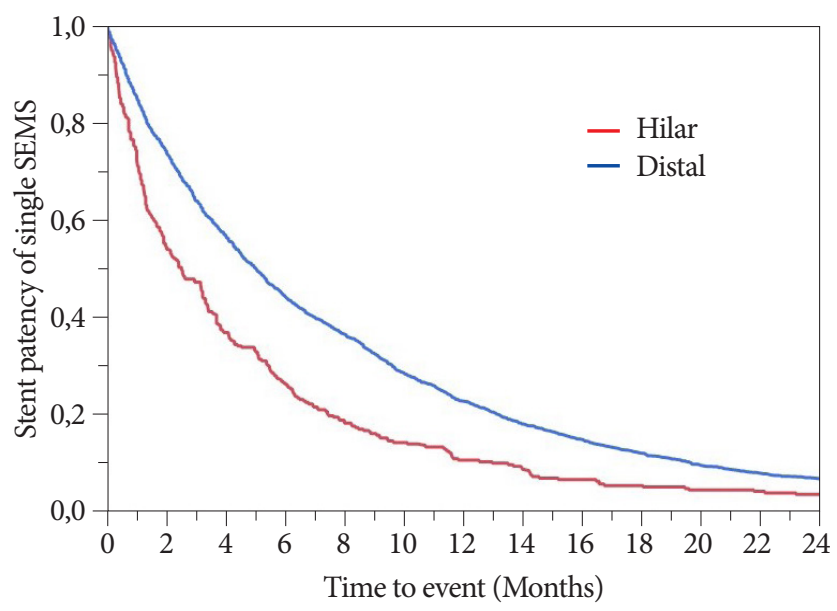

\begin{tabular}{|c|c|c|c|c|c|}
\hline \multirow[b]{2}{*}{ Stent patent } & \multicolumn{2}{|c|}{ Distal } & \multicolumn{2}{|c|}{ Hilar } & \multirow[b]{2}{*}{$p$} \\
\hline & $n$ & $\%$ & $n$ & $\%$ & \\
\hline 6 months & 830 & 44.1 & 88 & 26.6 & $<0.0001$ \\
\hline 12 months & 430 & 22.9 & 37 & 11.2 & $<0.0001$ \\
\hline 18 months & 227 & 12.1 & 19 & 5.7 & 0.0007 \\
\hline 24 months & 129 & 6.9 & 14 & 4.2 & 0.0733 \\
\hline
\end{tabular}

Fig. 3. Time to the need for endoscopic reintervention (in months) after hilar and distal single metal stent placement. SEMS, self-expanding metal stent (log-rank: chi-square [ChiSq] 47.07, $p>$ ChiSq<0.0001; Wilcoxon: ChiSq 66.13, $p>$ ChiSq $<0.0001)$

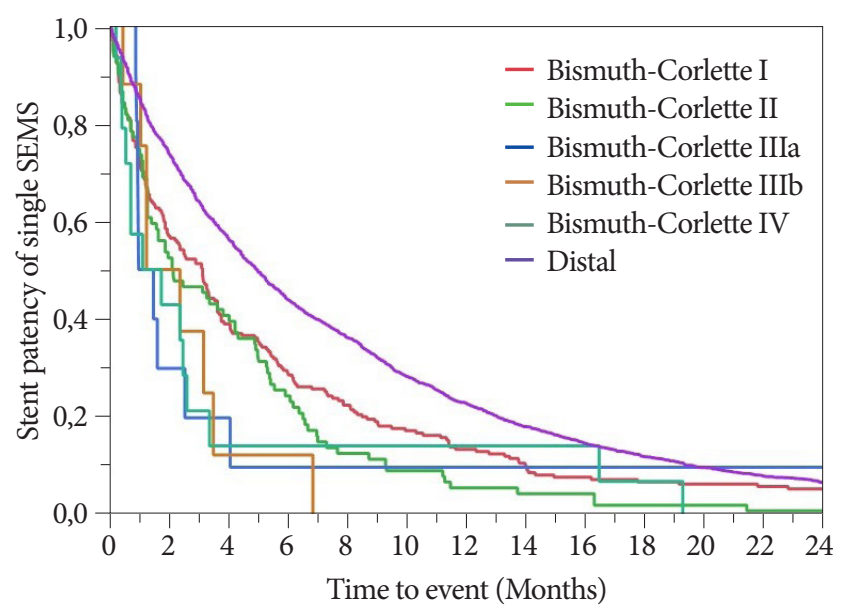

$2.01-6.00, p<0.001)$ than in patients with a DS (Table 3).

\section{DISCUSSION}

Our study, based on prospective data from a large and well-validated registry, is, to our knowledge, the first to directly compare the outcomes of endoscopic stenting for malignant strictures located in the distal and hilar (subdivided into different B-C types) locations of the biliary tree. Although the incidence of cholangiocarcinoma is increasing in Western countries, the distribution of malignant strictures between DSs (70\%) and HSs (30\%) in our study reflects the prevalence of pancreatic adenocarcinoma, cholangiocarcinoma, and gallbladder cancer found in populations worldwide. ${ }^{13}$

The superiority of SEMSs over plastic stents for malignant DSs and HSs and the equivalence of covered and uncovered SEMSs for DSs have been confirmed in multiple randomized trials. ${ }^{1-3}$ Whereas both covered and uncovered SEMSs could be used for B-C I HSs, probably with comparable results, uncovered SEMSs are used for B-C II-IV strictures to prevent the occlusion of biliary radicles covered by the expanded stent proximal to the stricture. ${ }^{14}$ The recommendations for HS management are generally weak, as they are based on low-level evidence. Studies are typically hampered by a multitude of variables and potential confounders, including the proximal and distal extent of strictures, liver functionality (presence of atrophied segments and number of segments drained), diverse underlying pathologies (cholangiocarcinoma vs. metastatic strictures), and access type (percutaneous vs. ERCP vs. endoscopic ultrasound). The presence of these multitude of variables results in small numbers for analysis, and statistically significant results are seldom reported.

The mean procedure time was shorter for DSs than for HSs and was similar between extrahepatic and intrahepatic HSs. These results were expected, as incrementally more proximal strictures could be technically more challenging to traverse with a guidewire owing to decreased thrust and increased angulation encountered in the hilum. The difficulty in se-

\begin{tabular}{|c|c|c|c|c|c|c|c|c|c|c|c|c|c|}
\hline \multirow[b]{2}{*}{ Stent patent } & \multicolumn{2}{|c|}{ Distal } & \multicolumn{2}{|c|}{ B-C I } & \multicolumn{2}{|c|}{ B-C II } & \multicolumn{2}{|c|}{ B-C IIIa } & \multicolumn{2}{|c|}{ B-C IIIb } & \multicolumn{2}{|c|}{ B-C IV } & \multirow[b]{2}{*}{$p$} \\
\hline & $n$ & $\%$ & $n$ & $\%$ & $n$ & $\%$ & $n$ & $\%$ & $n$ & $\%$ & $n$ & $\%$ & \\
\hline 6 months & 830 & 44.1 & 63 & 29.6 & 21 & 24.4 & 1 & 10 & 1 & 12.5 & 2 & 14.3 & $<0.0001$ \\
\hline 12 months & 430 & 22.85 & 29 & 13.6 & 5 & 5.8 & 1 & 10 & 0 & 0 & 2 & 14.3 & $<0.0001$ \\
\hline 18 months & 227 & 12.1 & 15 & 7.0 & 2 & 2.3 & 1 & 10 & 0 & 0 & 1 & 7.1 & 0.0212 \\
\hline 24 months & 129 & 6.9 & 12 & 5.7 & 1 & 1.2 & 1 & 10 & 0 & 0 & 0 & 0 & 0.2654 \\
\hline
\end{tabular}

Fig. 4. Time to the need for endoscopic reintervention (in months) after single metal stent placement for B-C types I-IV. SEMS, self-expanding metal stent; B-C, Bismuth-Corlette (log-rank: chi-square [ChiSq] 58.85, $p>$ ChiSq<0.0001; Wilcoxon: ChiSq 74.04, $p>$ ChiSq $<0.0001$ ). 
Table 3. Univariate and Multivariate analyses of the Risk for Reintervention after Single Metal Stent Placement

\begin{tabular}{|c|c|c|c|c|}
\hline & \multicolumn{2}{|c|}{ Univariate analysis } & \multicolumn{2}{|c|}{ Multivariate analysis } \\
\hline & $\begin{array}{c}\text { Hazard ratio }^{a} \\
\text { (95\% confidence interval) }\end{array}$ & $p$-Value & $\begin{array}{c}\text { Hazard ratio }^{\mathrm{a}} \\
(95 \% \text { confidence interval) }\end{array}$ & $p$-Value \\
\hline Hilar stricture & $3.26(1.89-5.59)$ & $<0.001$ & $3.47(2.01-6.00)$ & $<0.001$ \\
\hline Male sex & $1.85(1.12-3.07)$ & 0.017 & $1.97(1.18-3.27)$ & 0.009 \\
\hline Age $>75$ yrs & $0.98(0.60-1.62)$ & 0.951 & $1.08(0.65-1.78)$ & 0.775 \\
\hline ASA III-IV & $1.05(0.63-1.73)$ & 0.860 & $0.94(0.56-1.56)$ & 0.804 \\
\hline
\end{tabular}

ASA, American Society of Anesthesiologists.

${ }^{a}$ Cox proportional hazard analysis.

lectively cannulating specific intrahepatic ducts for bilateral or multisectoral stenting also adds to the procedure time. Postprocedural adverse events, specifically post-ERCP pancreatitis and cholangitis, more commonly occurred after hilar stenting than after distal stenting. It is known that the risk of post-ERCP pancreatitis is not influenced by performing an endoscopic sphincterotomy before SEMS deployment but is directly related to the procedure time, and the higher rates in our study may be related to the significantly longer procedure times. ${ }^{15}$ The cholangitis rates after distal endoscopic stenting for malignant obstruction vary depending on stent type (SEMS vs. plastic stent), ranging from $5 \%$ to $30 \%$ in randomized controlled trials. ${ }^{16,17}$ Prospective studies on hilar endoscopic stenting for malignant obstruction have reported cholangitis rates ranging between $4.7 \%$ and $16.6 \% .{ }^{18-21}$ Cholangitis after hilar stenting is multifactorial and can be the result of procedural factors, such as inadvertent filling of bile ducts not drained by the placed stent, and tumor progression. Interestingly, our data did not show significant differences in 30-day adverse events (including cholangitis) when comparing intrahepatic and extrahepatic HS stenting. Although the definitions of cholangitis vary, our results are in contrast with those of previous publications reporting cholangitis rates for B-C I, II, and III-IV of $4 \%, 10 \%$, and $57.7 \%$, respectively, and those reporting that BC IV stricture stenting was associated with higher cholangitis rates. $^{22,23}$

The mean patency duration after distal SEMS placement has been reported to be 250 days, and randomized trials report 6and 12 -month patency rates varying between $68 \%-78 \%$ and $32 \%-55 \% .{ }^{19,24}$ Our study found an estimated 6-month patency rate of $44 \%$, with $56 \%$ of the patients requiring reintervention. For hilar stents, patency rates of $30 \%$ and $17 \%$ at 6 and 12 months, respectively, have been reported in randomized controlled trials, although most reports failed to investigate differences among the B-C types. ${ }^{18,25}$ Importantly, our data showed estimated 6- and 12-month patency rates for hilar stents of $27 \%$ and $11 \%$, respectively, with reintervention required in $73 \%$ at 6 months and in $89 \%$ at 12 months. In multivariate analysis, male sex and HS location were identified as risk factors for reintervention, with the risk of reintervention after HS stenting being three times higher than that after DS stenting.

In a retrospective report on 61 patients undergoing hilar stenting, Rerknimitr et al. reported mean patency durations of 87,69 , and 41 days for B-C types I, II, and III-IV respectively. ${ }^{22}$ The 6-month reintervention rates in the current study ranged from $70 \%$ for B-C I strictures to $86 \%$ for BC IV strictures. This is likely the effect of proximal disease progression occluding initially drained segments that were colonized, resulting in cholangitis and requiring additional interventions. Although the numbers were small, the highest reintervention rate at 6 months was observed in SEMSs placed in the right hepatic duct (90\%), in contrast to previous reports of decreased patency in left-sided SEMSs, but highlighting the fact that bilateral or multisectoral drainage should probably be pursued in more advanced $\mathrm{B}-\mathrm{C}$ types. ${ }^{26}$ Placement of a single stent in patients with a B-C I stricture allows for drainage of the whole liver, comparable to single stent placement in DSs. It is interesting to note the $14 \%$ difference in patency rates after DS (44\%) and B-C I stricture (30\%) stenting in our patients.

To our knowledge, this is the largest analysis of hilar stent performance as it occurs in the population at large. However, the study has a number of limitations. Hilar strictures were defined as obstructions involving or proximal to the opening of the cystic duct, which, owing to variation in the level of the cystic duct junction, may have resulted in an overlap between distal and B-C I strictures in terms of actual stricture position. Although there is still no consensus on an alternative definition, the use of a measured cutoff, such as the distal half of the extrahepatic bile duct for DSs, as proposed by the Japanese Society of Hepato-Biliary-Pancreatic Surgery, would be more 
appropriate and would probably generate more clinically relevant data. ${ }^{27}$ As prophylactic nonsteroidal anti-inflammatory and antibiotic use was only introduced as part of GallRiks data capturing in the latter period of participant inclusion, these confounders could not be accounted for. Death without reintervention was treated as a censored event; however, the actual stent patency at the time of death could not be determined, and random censoring and an occluded stent at the time of death could not be excluded. Percutaneous reintervention for stent dysfunction and patients undergoing curative resection or palliative chemotherapy could not be accounted for, as nonendoscopic interventions are not entered into the registry. Not accounting for these groups probably underestimated the number of stent failures, especially for intrahepatic HSs.

This study underscores the difficulties encountered in investigating stenting for malignant HSs. The study simplified and did not cover the whole spectrum of hilar stenting, as patients treated with plastic or multiple stents and percutaneous or endoscopic ultrasound-placed stents were excluded. Randomized trials that have generated strong evidence about the numerous issues concerning DS stenting cannot be replicated for HS stenting. Analyses of large population-based cohorts could serve as a platform for studies to obtain more robust data. However, simple ERCP registries such as GallRiks, not specifically designed for HSs, lack granular information on key variables, thus precluding in-depth analyses of important unanswered questions.

In conclusion, our study, based on a large and well-validated population-based registry, confirms that endoscopic treatment of malignant HS has high complication rates and high reintervention rates. The number of variables that need to be accounted for in this population precludes comprehensive randomized trials. Dedicated multi-institutional registries specifically designed to answer research questions about hilar stenting are needed.

Conflicts of Interest

The authors have no potential conflicts of interest.

Funding

This study was supported by the South African Medical Research Council through the Self-Initiated Research Grant.

\author{
Author Contributions \\ Conceptualization: Urban Arnelo, Lars Enochsson \\ Data curation: Jeanne Lubbe, UA, Eduard Jonas, LE \\ Formal analysis: JL, Gabriel Sandblom, EJ, LE \\ Funding acquisition: JL \\ Investigation: JL, GS, UA, EJ \\ Methodology: JL, GS, EJ, LE \\ Project administration: LE \\ Resources: GS, UA, LE \\ Software: GS, LE
}

Supervision: LE

Validation

Visualization

Writing-original draft: JL

Writing-review\&editing: JL, GS, UA,EJ, LE

ORCID
Jeanne Lubbe:

Urban Arnelo:

Eduard Jonas:

Lars Enochsson:
Gabriel Sandblom: https://orcid.org/0000-0001-8397-8685 https://orcid.org/0000-0002-7416-4951 https://orcid.org/0000-0002-1843-5673 https://orcid.org/0000-0003-0123-256X https://orcid.org/0000-0001-8947-4736

\section{REFERENCES}

1. Almadi MA, Barkun A, Martel M. Plastic vs. self-expandable metal stents for palliation in malignant biliary obstruction: a series of meta-analyses. Am J Gastroenterol 2017;112:260-273.

2. Hong W, Chen X, Wu W-Z, Zhu Q, Chen X. Metal versus plastic stents for malignant biliary obstruction: an update meta-analysis. Clin Res Hepatol Gastroenterol 2013;37:496-500.

3. Tringali A, Hassan C, Rota M, Rossi M, Mutignani M, Aabakken L. Covered vs. uncovered self-expandable metal stents for malignant distal biliary strictures: a systematic review and meta-analysis. Endoscopy 2018;50:631-641.

4. Baer HU, Rhyner M, Stain SC, et al. The effect of communication between the right and left liver on the outcome of surgical drainage for jaundice due to malignant obstruction at the hilus of the liver. HPB Surg 1994;8:27-31.

5. Vienne A, Hobeika E, Gouya H, et al. Prediction of drainage effectiveness during endoscopic stenting of malignant hilar strictures: the role of liver volume assessment. Gastrointest Endosc 2010;72:728-735.

6. Ashat M, Arora S, Klair JS, Childs CA, Murali AR, Johlin FC. Bilateral vs unilateral placement of metal stents for inoperable high-grade hilar biliary strictures: a systemic review and meta-analysis. World J Gastroenterol 2019;25:5210-5219.

7. Aghaie Meybodi M, Shakoor D, Nanavati J, et al. Unilateral versus bilateral endoscopic stenting in patients with unresectable malignant hilar obstruction: a systematic review and meta-analysis. Endosc Int Open 2020;8:E281-E290.

8. Rystedt J, Montgomery A, Persson G. Completeness and correctness of cholecystectomy data in a national register--GallRiks. Scand J Surg 2014;103:237-244.

9. Enochsson L, Blohm M, Sandblom G, et al. Inversed relationship between completeness of follow-up and coverage of postoperative complications in gallstone surgery and ERCP: a potential source of bias in patient registers. BMJ Open 2018;8:e019551.

10. Bismuth $\mathrm{H}, \mathrm{Nakache} \mathrm{R}$, Diamond T. Management strategies in resection for hilar cholangiocarcinoma. Ann Surg 1992;215:31-38.

11. Dumonceau J-M, Kapral C, Aabakken L, et al. ERCP-related adverse events: european society of gastrointestinal endoscopy (ESGE) guideline. Endoscopy 2020;52:127-149.

12. Isayama H, Hamada T, Yasuda I, et al. TOKYO criteria 2014 for transpapillary biliary stenting. Dig Endosc 2015;27:259-264

13. Tyson GL, Ilyas JA, Duan Z, et al. Secular trends in the incidence of cholangiocarcinoma in the USA and the impact of misclassification. Dig Dis Sci 2014;59:3103-3110.

14. Dumonceau J-M, Tringali A, Papanikolaou IS, et al. Endoscopic biliary stenting: indications, choice of stents, and results: european society of gastrointestinal endoscopy (ESGE) clinical guideline - updated october 2017. Endoscopy 2018;50:910-930.

15. Sofi AA, Nawras A, Alaradi OH, Alastal Y, Khan MA, Lee WM. Does 
endoscopic sphincterotomy reduce the risk of post-endoscopic retrograde cholangiopancreatography pancreatitis after biliary stenting? A systematic review and meta-analysis. Dig Endosc 2016;28:394-404.

16. Moses PL, Alnaamani KM, Barkun AN, et al. Randomized trial in malignant biliary obstruction: plastic vs partially covered metal stents. World J Gastroenterol 2013;19:8638-8646.

17. Schmidt A, Riecken B, Rische S, et al. Wing-shaped plastic stents vs. self-expandable metal stents for palliative drainage of malignant distal biliary obstruction: a randomized multicenter study. Endoscopy 2015;47:430-436.

18. Sangchan A, Kongkasame W, Pugkhem A, Jenwitheesuk K, Mairiang P. Efficacy of metal and plastic stents in unresectable complex hilar cholangiocarcinoma: a randomized controlled trial. Gastrointest Endosc 2012;76:93-99.

19. Zorrón Pu L, de Moura EGH, Bernardo WM, Baracat FI, et al. Endoscopic stenting for inoperable malignant biliary obstruction: a systematic review and meta-analysis. World J Gastroenterol 2015;21:13374-13385.

20. De Palma GD, Galloro G, Siciliano S, Iovino P, Catanzano C. Unilateral versus bilateral endoscopic hepatic duct drainage in patients with malignant hilar biliary obstruction: results of a prospective, randomized, and controlled study. Gastrointest Endosc 2001;53:547-553.

21. Lee TH, Kim TH, Moon JH, et al. Bilateral versus unilateral placement of metal stents for inoperable high-grade malignant hilar biliary strictures: a multicenter, prospective, randomized study (with video). Gas- trointest Endosc 2017;86:817-827.

22. Rerknimitr R, Kladcharoen N, Mahachai V, Kullavanijaya P. Result of endoscopic biliary drainage in hilar cholangiocarcinoma. J Clin Gastroenterol 2004;38:518-523.

23. Xia M-X, Wang S-P, Wu J, et al. The risk of acute cholangitis after endoscopic stenting for malignant hilar strictures: a large comprehensive study. J Gastroenterol Hepatol 2020;35:1150-1157.

24. Conio M, Mangiavillano B, Caruso A, et al. Covered versus uncovered self-expandable metal stent for palliation of primary malignant extrahepatic biliary strictures: a randomized multicenter study. Gastrointest Endosc 2018;88:283-291.e3.

25. Mukai T, Yasuda I, Nakashima M, et al. Metallic stents are more efficacious than plastic stents in unresectable malignant hilar biliary strictures: a randomized controlled trial. J Hepatobiliary Pancreat Sci 2013;20:214222.

26. Miura S, Kanno A, Masamune A, et al. Risk factors for recurrent biliary obstruction following placement of self-expandable metallic stents in patients with malignant perihilar biliary stricture. Endoscopy 2016;48:536545 .

27. Miyazaki M, Ohtsuka M, Miyakawa S, et al. Classification of biliary tract cancers established by the Japanese Society of Hepato-Biliary-Pancreatic Surgery: 3(rd) English edition. J Hepatobiliary Pancreat Sci 2015;22:181196. 